\title{
Use of Drugs with Anticholinergic Properties at Hospital Admission Associated with Mortality in Older Patients: A Danish Nationwide Register-Based Cohort Study
}

\author{
Søren Ramsdal Sørensen ${ }^{1,2}$. Jeppe Dalskov Frederiksen ${ }^{1,2}$. Pavithra Laxsen Anru ${ }^{3,4}$ (C) Tahir Masud ${ }^{1,2,5}$. \\ Mirko Petrovic $^{6} \oplus$. Jens-Ulrik Rosholm ${ }^{1,2}$. Jesper Ryg ${ }^{1,2}(1)$
}

Accepted: 7 July 2021 / Published online: 19 August 2021

(C) The Author(s) 2021

\begin{abstract}
Background Use of drugs with anticholinergic properties (DAP) has a negative impact on older people.

Objective Our aim was to examine the association between DAP at hospital admission and mortality in older patients.

Patients and Methods We performed a nationwide population-based cohort study including patients aged $\geq 65$ years admitted to Danish geriatric medicine departments during 2005-2014. National health registers were used to link with individuallevel data. Patients were followed to emigration, death, or study termination (31 December 2015). DAP was defined as medications included in the anticholinergic cognitive burden (ACB) scale, which assigns each DAP a score between 1 and 3. The individual ACB score was calculated and the number of DAP counted. We used Cox proportional-hazard regressions to estimate the crude and adjusted hazard ratios adjusting for age, activities of daily living, marital status, index admission period, BMI, and prior hospitalizations (model 1), and additionally Charlson Comorbidity Index (model 2).

Results We included 74,589 patients aged (median [IQR]) 83 (77-88) years. Use of one or more DAP (62.5\%) was associated with increased mortality compared with those with no use $(p<0.001)$. In the fully adjusted model 2 , compared with no use, higher mortality risks (HR [95\% CI]) were seen with ACB score of 2 and number of DAP $\geq 5$ for 30-day (1.46 [1.32-1.61] and 1.46 [1.09-1.95]), 1-year (1.34 [1.28-1.41] and 1.48 [1.29-1.70]), and overall mortality (1.27 [1.23-1.31] and 1.44 [1.31-1.59]), respectively.

Conclusions Use of DAP at hospital admission is associated with short- and long-term mortality in geriatric patients. Deprescribing studies are warranted to study whether the impact on mortality can be attenuated.
\end{abstract}

Søren Ramsdal Sørensen and Jeppe Dalskov Frederiksen: co-first authors.

Jesper Ryg

jesper.ryg@rsyd.dk

1 Department of Geriatric Medicine, Odense University Hospital, J.B. Winsløws Vej 4, 5000 Odense C, Denmark

2 Geriatric Research Unit, Department of Clinical Research, University of Southern Denmark, Odense, Denmark

3 Research Unit of Clinical Epidemiology, Department of Clinical Research, University of Southern Denmark, Odense, Denmark

4 Center for Clinical Epidemiology, Odense University Hospital, Odense, Denmark

5 Geriatric Department, Nottingham University Hospital, Nottingham, UK

6 Deaprtment of Geriatrics, Ghent University Hospital, Ghent, Belgium 


\section{Key Points}

Our study found a dose-response association between increased anticholinergic cognitive burden score as well as increased number of drugs with anticholinergic properties (DAP) at hospital admission and mortality in older patients.

The use of DAP was significantly associated with all-cause mortality even when adjusting for important confounders including comorbidities and activities of daily living.

In terms of mortality, our findings suggest that counting the number of DAP might be as relevant as calculating the anticholinergic cognitive burden score.

\section{Introduction}

Current demographic trends mean that the proportion of older people will increase substantially over the next 30 years [1]. Moreover, the prevalence of multimorbidity and disability is increasing with age [2]. The use of medications is consequently also on the rise and polypharmacy has become a major issue in the older population [3, 4]. Older people are more exposed to the negative effects of polypharmacy, in part because of multimorbidity and agerelated changes in pharmacokinetics and pharmacodynamics $[4,5]$. One of the major groups of medications contributing to polypharmacy in the older population are drugs with anticholinergic properties (DAP) [6]. Accordingly, research is beginning to focus on deprescribing DAP and the impact on outcomes in older people [7, 8].

DAP act on acetylcholine receptors in the central and peripheral nerve systems causing various adverse effects, and therefore must be used judiciously. These adverse effects are both cognitive and physical in nature and include delirium, constipation, urinary retention, dry mouth, acute glaucoma precipitation, falls, and cardiovascular outcomes [9-13].

Several scales have been used to quantify the burden of DAP. The most widely used scales include the Drug Burden Index, the Anticholinergic Drug Scale, the Anticholinergic Risk Scale, and the anticholinergic cognitive burden (ACB) scale [14-17]. The ACB scale is one of the oldest and most validated scales [18, 19], and some researchers suggest an association between ACB score and mortality [10, 20-25], whilst others find no association [11, 26]. However, even with multiple studies showing an association between
ACB score and mortality, there is no clear dose-response relationship.

Several other factors are associated with mortality in older people. Among important factors are multimorbidity and the individuals' functional level expressed as activities of daily living (ADL) [27-30]. The aim of the present study was to examine the association between use of DAP at hospital admission and mortality in a nationwide cohort of acutely admitted geriatric patients when taking comorbidities and ADL into account.

\section{Methods}

This was a nationwide register-based longitudinal cohort study in acutely hospitalized geriatric patients. Our primary outcome of interest was all-cause mortality.

\subsection{Data Sources, Study Population, and Variables}

Setting and participants have previously been described in detail elsewhere [27]. In short, the study combines data from four different Danish national registers: the Danish Civil Registry System [31], the Danish National Database of Reimbursed Prescriptions [32], the Danish National Database of Geriatrics [33], and the Danish National Patient Register [34]. Data was linked on an individual level using the unique social security number given to all persons in Denmark at birth or upon immigration. The study population was identified through the Danish National Database of Geriatrics and included all patients aged $\geq 65$ years with their first registered hospitalization at a Danish geriatric department from the start of 2005 to the end of 2014. Patients were followed up until death, emigration, or the end of the study on December 31, 2015. Data on marital status, emigration, and death were extracted from the Danish Civil Registry System whereas prior hospitalizations and diseases were extracted from the Danish National Patient Register. We used the Charlson Comorbidity Index (CCI) to report data on comorbidity. CCI is associated with mortality and takes comorbidity into account by scoring 19 chronic diseases according to the number and severity of disease [35]. We calculated CCI using ICD-10 codes from 10 years prior to individual index admission and reported it in categories of $0,1,2,3,4$, or $\geq 5$ points. Data on patient's functional level and body mass index (BMI), which are other covariates known to impact mortality, were also included.

One way to describe functional level is to evaluate ADL. The Danish National Database of Geriatrics holds data on Barthel Index (BI), which is scored routinely upon hospital admission and used to measure patients' ADLs [36]. Ten different aspects of ADL are assessed and scored numerically with a combined score ranging from 0 (completely 
dependent) to 100 (completely independent). BI was grouped into four standard diagnostic categories, 0-24, $25-49,50-79$, and 80-100, according to the national Danish version of the statistical classification of diseases [37]. Weight and height were extracted from the Danish National Database of Geriatrics and BMI was then calculated as weight in kilograms divided by height in meters squared and divided into four standard categories, $<18.5,18.5-24.9$, 25-29.9, or $\geq 30$, according to the World Health Organization. The number of medications were defined as medications purchased up to 120 days prior to the index date. This cut-off was chosen since most medications given for long-term treatment in Denmark are administered in 100-pill packages [38]. Information about redeemed prescriptions was provided by the Danish National Database of Reimbursed Prescriptions [32] using Anatomical Therapeutic Chemical (ATC) codes. Medications in the variable 'all medications' in the baseline characteristics shown in Table 1 were counted at the fourth level of the ATC code. DAP were the specific variable of interest. These were defined as medications included in the ACB scale identified by counting the fifth level of the ATC [17, 39] (Supplementary Table 1, see ESM). The ACB score separates DAP into three different groups. Medications with serum anticholinergic activity and in vitro affinity to the muscarinic receptor are assigned a score of one point. If these medications are known to have clinically relevant anticholinergic effects, the scores are two or three, based on their permeability of the blood-brain barrier and their ability to induce delirium [17]. We calculated the ACB score for each included patient in this study and furthermore counted the total number of DAP according to the ACB-listed medications.

\subsection{Statistics}

Descriptive statistics were reported in contingency tables as mean and standard deviation (SD) for normally distributed data and as median and interquartile range (IQR) for skewed data. Follow-up started from the patient's first registration of hospital admission at a geriatric department to the date of emigration, death, or end of the follow-up period (31 December 2015), whichever came first. We used Cox proportional-hazard regressions to estimate the crude and adjusted hazard ratios with corresponding $95 \%$ confidence interval (95\% CI) for the following outcomes: overall mortality, 30-day mortality, and 1-year mortality. The multivariable models were adjusted for age, BI, marital status, period of index admission, BMI, prior hospital admission 1 year prior to index admission in model 1 and CCI was further added as confounder in model 2. All univariable and multivariable analyses were performed on the total cohort and further stratified on gender at birth. We used the Wald statistics to test the statistical significance of the categorical variables included in the multivariable Cox regression models. For each model, where the variables of interest were ACB score or number of DAP, we computed receiver operating characteristic (ROC) curves and their area under the curve (AUC) with 95\% CIs for the fully adjusted model 2 . Furthermore, a graphical presentation of the variable of interest was presented, where the ACB score or number of DAP was plotted as a continuous variable against the risk of overall mortality. $P$ values $<0.05$ indicated the statistical significance, and all analyses were performed using STATA version 14.2 (StataCorp, College Station, TX, USA).

\subsection{Ethics}

This study was approved by the Danish data protection agency (2012580018, J.nr. 16/23359). Informed consent was not necessary according to Danish legislation on medical ethics due to the register-based study design. Data are reported according to STROBE (Strengthening the Reporting of Observational studies in Epidemiology) guidelines [40].

\section{Results}

We included a total of 74,589 patients, consisting of 46,815 women and 27,774 men with a median (IQR) age of 83 (77-88) years. The mean \pm SD number of all prescribed medications was $6.4 \pm 3.9$ in the total cohort, whereas the mean \pm SD number of DAP was $1.1 \pm 1.2$ and the mean \pm SD ACB score was $1.3 \pm 1.5$. The baseline characteristics of the study population are summarized in Table 1 . The median follow-up time of the total cohort was 2 years. During follow-up, a total of 51,197 participants died with a median survival (95\% CI) of $3.1(3.1-3.2)$ years in women and $2.1(2.0-2.1)$ years in men.

The majority of patients (62.5\%) received DAP. Few patients received medications with an ACB score of two or three while a score of one accounted for $88.1 \%$ of the overall anticholinergic intake. The three most used DAP in the cohort (furosemide, metoprolol, and digoxin) accounted for $55.4 \%$ of the overall anticholinergic intake and the ten most used DAP (furosemide, metoprolol, digoxin, warfarin, dipyridamole, morphine, codeine, isosorbide, fentanyl, and tolterodine) for $88.9 \%$ (Supplementary Table 1, see ESM).

Table 2 illustrates risk of overall, 30-day, and 1-year mortality with increasing ACB score for the total cohort, whereas Supplementary Table 2 (see ESM) illustrates the risks for women and men separately. Patients prescribed DAP $(62.5 \%)$ had increased mortality compared with those who were not prescribed any $(37.5 \%)(p<0.001)$. The univariable analysis showed an increasing risk of overall mortality (HR [95\% CI]) in the total cohort with an ACB score 
Table 1 Baseline characteristics of the study population

\begin{tabular}{|c|c|c|c|}
\hline & $\begin{array}{l}\text { Total cohort } \\
N=74,589\end{array}$ & $\begin{array}{l}\text { Women } \\
N=46,815\end{array}$ & $\begin{array}{l}\text { Men } \\
N=27,774\end{array}$ \\
\hline \multicolumn{4}{|l|}{ ACB score ${ }^{a}$} \\
\hline Mean \pm SD & $1.3 \pm 1.5$ & $1.3 \pm 1.6$ & $1.3 \pm 1.5$ \\
\hline Median (IQR) & $1(0-2)$ & $1(0-2)$ & $1(0-2)$ \\
\hline 0 & $27,971(37.50)$ & $17,744(37.90)$ & $10,227(36.82)$ \\
\hline 1 & $19,791(26.53)$ & $12,431(26.55)$ & $7360(26.50)$ \\
\hline 2 & $11,201(15.02)$ & 6874 (14.68) & $4327(15.58)$ \\
\hline 3 & $7384(9.90)$ & $4612(9.85)$ & $2772(9.98)$ \\
\hline 4 & 3908 (5.24) & $2473(5.28)$ & $1435(5.17)$ \\
\hline$\geq 5$ & 3125 (4.19) & $2010(4.29)$ & $1115(4.01)$ \\
\hline Missing, $n(\%)$ & 1209 (1.62) & $671(1.43)$ & $538(1.94)$ \\
\hline \multicolumn{4}{|l|}{ No. of DAP ${ }^{a}$} \\
\hline Mean \pm SD & $1.1 \pm 1.2$ & $1.1 \pm 1.2$ & $1.1 \pm 1.2$ \\
\hline Median (IQR) & $1(0-2)$ & $1(0-2)$ & $1(0-2)$ \\
\hline 0 & $27,971(37.50)$ & $17,744(37.90)$ & $10,227(36.82)$ \\
\hline 1 & $22,461(30.11)$ & $14,153(30.23)$ & 8308 (29.91) \\
\hline 2 & $13,519(18.12)$ & 8369 (17.88) & $5150(18.54)$ \\
\hline 3 & $6338(8.50)$ & 3917 (8.37) & $2421(8.72)$ \\
\hline 4 & 2375 (3.18) & $1481(3.16)$ & $894(3.22)$ \\
\hline$\geq 5$ & $716(0.96)$ & $480(1.03)$ & $236(0.85)$ \\
\hline Missing, $n(\%)$ & 1209 (1.63) & $671(1.43)$ & $538(1.94)$ \\
\hline \multicolumn{4}{|l|}{ All medications ${ }^{\mathrm{a}}$} \\
\hline Mean \pm SD & $6.4 \pm 3.9$ & $6.5 \pm 3.9$ & $6.3 \pm 3.9$ \\
\hline Median (IQR) & $6(4-9)$ & $6(4-9)$ & $6(3-9)$ \\
\hline 0 & $2856(3.83)$ & $1621(3.46)$ & 1235 (4.45) \\
\hline 1 & $3847(5.16)$ & $2291(4.89)$ & $1556(5.60)$ \\
\hline 2 & $5066(6.79)$ & 3065 (6.55) & $2001(7.20)$ \\
\hline 3 & $6316(8.47)$ & $3926(8.39)$ & $2390(8.61)$ \\
\hline 4 & $7210(9.67)$ & 4465 (9.54) & $2745(9.88)$ \\
\hline 5 & $7580(10.16)$ & $4780(10.21)$ & $2800(10.08)$ \\
\hline 6 & 7494 (10.05) & $4830(10.32)$ & 2664 (9.59) \\
\hline 7 & $6901(9.25)$ & $4352(9.30)$ & $2549(9.18)$ \\
\hline 8 & $6120(8.20)$ & $3973(8.49)$ & 2147 (7.73) \\
\hline 9 & $5155(6.91)$ & $3363(7.18)$ & $1792(6.45)$ \\
\hline$\geq 10$ & $14,835(19.89)$ & $9478(20.25)$ & $5357(19.29)$ \\
\hline Missing & $1209(1.62)$ & $671(1.43)$ & $538(1.94)$ \\
\hline Barthel Index, median [IQR] & $54(29-77)$ & $55(30-77)$ & $52(26-77)$ \\
\hline $80-100, n(\%)$ & $15,801(21.18)$ & $9969(21.29)$ & $5832(21.00)$ \\
\hline $50-79, n(\%)$ & $22,509(30.18)$ & $14,681(31.36)$ & $7828(28.18)$ \\
\hline $25-49, n(\%)$ & $16,479(22.09)$ & $10,375(22.16)$ & $6104(21.98)$ \\
\hline $0-24, n(\%)$ & $15,170(20.34)$ & 8979 (19.18) & $6191(22.29)$ \\
\hline Missing, $n(\%)$ & $4630(6.21)$ & $2811(6.00)$ & $1819(6.55)$ \\
\hline Age (years), median [IQR] & $83(77-88)$ & $84(79-89)$ & $81(76-86)$ \\
\hline $65-74, n(\%)$ & $12,076(16.19)$ & $6117(13.07)$ & $5959(21.46)$ \\
\hline $75-84, n(\%)$ & $30,603(41.03)$ & $18,361(39.22)$ & $12,242(44.08)$ \\
\hline $85-94, n(\%)$ & $28,988(38.86)$ & $20,092(42.92)$ & $8896(32.03)$ \\
\hline$\geq 95, n(\%)$ & $2922(3.92)$ & $2245(4.80)$ & $677(2.44)$ \\
\hline \multicolumn{4}{|l|}{ Marital status, $n(\%)$} \\
\hline Unmarried & $4851(6.50)$ & $2733(5.84)$ & $2118(7.63)$ \\
\hline Married & $21,639(29.01)$ & $8268(17.66)$ & $13,371(48.14)$ \\
\hline
\end{tabular}


Table 1 (continued)

\begin{tabular}{|c|c|c|c|}
\hline & $\begin{array}{l}\text { Total cohort } \\
N=74,589\end{array}$ & $\begin{array}{l}\text { Women } \\
N=46,815\end{array}$ & $\begin{array}{l}\text { Men } \\
N=27,774\end{array}$ \\
\hline Divorced & $9204(12.34)$ & $5763(12.31)$ & $3441(12.39)$ \\
\hline Widowed & $38,881(52.13)$ & $30,044(64.18)$ & $8837(31.82)$ \\
\hline Missing & $14(0.02)$ & $7(0.01)$ & $7(0.03)$ \\
\hline \multicolumn{4}{|l|}{ Period of admission } \\
\hline $2005-2009$ & $31,357(42.04)$ & $20,432(43.64)$ & $10,925(39.34)$ \\
\hline 2010-2014 & $43,232(57.96)$ & $26,383(56.36)$ & $16,849(60.66)$ \\
\hline $\mathrm{BMI}\left(\mathrm{kg} / \mathrm{m}^{2}\right)$ mean $\pm \mathrm{SD}$ & $23.9 \pm 5.1$ & $23.6 \pm 5.3$ & $24.5 \pm 4.7$ \\
\hline$<18.5, n(\%)$ & $7087(9.50)$ & $5446(11.63)$ & $1641(5.91)$ \\
\hline $18.5-24.9, n(\%)$ & $30,111(40.37)$ & $18,982(40.55)$ & $11,129(40.07)$ \\
\hline $25-29.9, n(\%)$ & $15,060(20.19)$ & $8659(18.50)$ & $6401(23.05)$ \\
\hline$\geq 30, n(\%)$ & $6637(8.90)$ & $4097(8.75)$ & $2540(9.15)$ \\
\hline Missing, $n(\%)$ & $15,694(21.04)$ & $9631(20.57)$ & $6063(21.83)$ \\
\hline Charlson Comorbidity Index, median $[\mathrm{IQR}]^{\mathrm{b}}$ & $2(1-3)$ & $2(1-3)$ & $2(1-4)$ \\
\hline $0, n(\%)$ & $13,169(17.66)$ & $9814(20.96)$ & $3355(12.08)$ \\
\hline $1, n(\%)$ & $19,625(26.31)$ & $13,230(28.26)$ & $6395(23.03)$ \\
\hline $2, n(\%)$ & $15,786(21.16)$ & $9945(21.24)$ & $5841(21.03)$ \\
\hline $3, n(\%)$ & $10,887(14.60)$ & $6301(13.46)$ & $4586(16.51)$ \\
\hline $4, n(\%)$ & $6627(8.88)$ & $3535(7.55)$ & $3092(11.13)$ \\
\hline$\geq 5, n(\%)$ & $8494(11.39)$ & $3989(8.52)$ & $4505(16.22)$ \\
\hline Missing & $1(0.00)$ & $1(0.00)$ & $0(0.0)$ \\
\hline Prior hospital admission 1 year, median (IQR) & $0(0-1)$ & $0(0-1)$ & $1(0-2)$ \\
\hline $0, n(\%)$ & $39,685(53.20)$ & $25,924(55.38)$ & $13,761(49.55)$ \\
\hline $1-2, n(\%)$ & $26,650(35.73)$ & $16,478(35.20)$ & $10,172(36.62)$ \\
\hline$\geq 3, n(\%)$ & $8253(11.06)$ & $4412(9.42)$ & 3841 (13.83) \\
\hline Missing & $1(0.00)$ & $1(0.00)$ & $0(0.0)$ \\
\hline
\end{tabular}

ACB score was calculated according to Supplementary Table 1 (see ESM). Normal distributed data are presented with mean \pm SD whereas non-normal distributed data are presented with both median (IQR) and mean $\pm \mathrm{SD}$

$A C B$ anticholinergic cognitive burden, $B M I$ body mass index, $D A P$ drugs with anticholinergic properties, $I Q R$ interquartile range, $S D$ standard deviation

${ }^{a}$ All redeemed prescriptions were included, except from the following ATC codes: B05x (blood substitutes and perfusion solutions), B06x (other hematological agents), D09x (medicated dressings), J07x (vaccines), N01x (anesthetics) and Vx (various)

${ }^{\mathrm{b}}$ The Charlson Comorbidity Index was calculated based on hospital discharge diagnoses during the 10 years before baseline

of $1(1.23[1.20-1.25])$ and a score of $2(1.40[1.37-1.44])$. The risk was still increased but did not increase further with scores of 3 (1.36 [1.32-1.40]), 4 (1.36 [1.32-1.41]), or $\geq 5$ (1.32 [1.26-1.38]) (Table 2). ACB score was associated with both increased short- and long-term mortality. The highest risk of mortality (HR [95\% CI]) was found at 30 days in patients with an ACB score of 2 (1.64 [1.52-1.77]) (Table 2). In women, the highest overall mortality risk (HR [95\% CI]) was seen with an ACB score of 2 (1.40 [1.35-1.45]) and for men the highest risk was seen with an ACB score of 4 (1.50 [1.40-1.59]) (Supplementary Table 2a and 2b, see ESM).

In the multivariable analysis, the ACB score remained significantly associated with increased risk of overall mortality. The risk increased with an increasing ACB score up to
2 and remained increased but levelled off with ACB scores $\geq 3$. Risk of overall mortality (HR [95\% CI]) for model 2 were ACB 1 (1.14 [1.11-1.17]), ACB 2 (1.27 [1.23-1.31]), ACB 3 (1.24 [1.20-1.28]), ACB 4 (1.23 [1.17-1.29], and $\mathrm{ACB} \geq 5$ (1.24 [1.18-1.31]), respectively (Table 2). Figure 1a shows a ROC curve of model 2 overall mortality with an AUC of 0.7884. Including both models, ACB score was also associated with increased mortality, both short and long term. The strongest association was seen after 30 days with a decreasing trend towards 1 year. The highest risk of mortality (HR [95\% CI]) was found with a score of 2 in model 1 (1.65 [1.50-1.82]) after 30 days (Table 2). For women, the highest overall risk of mortality (HR [95\% CI]) in both models was seen with an ACB score of $\geq 5$ : model 1 (1.41 
Table 2 Univariable and multivariable hazard ratios and corresponding $95 \%$ confidence intervals for overall, 30-day, and 1-year mortality according to the anticholinergic cognitive burden (ACB) score in the total cohort

\begin{tabular}{|c|c|c|c|}
\hline & \multirow[t]{2}{*}{$\begin{array}{l}\text { Univariable } \\
\text { HR }(95 \% \text { CI })\end{array}$} & \multicolumn{2}{|l|}{$\begin{array}{l}\text { Multivariable } \\
\text { HR }(95 \% \mathrm{CI})\end{array}$} \\
\hline & & Model 1 & Model 2 \\
\hline \multicolumn{4}{|c|}{ Overall mortality } \\
\hline \multicolumn{4}{|c|}{ ACB score } \\
\hline 0 & 1 (reference) & 1 (reference) & 1 (reference) \\
\hline 1 & $1.23(1.20-1.25)$ & $1.21(1.18-1.24)$ & $1.14(1.11-1.17)$ \\
\hline 2 & $1.40(1.37-1.44)$ & $1.39(1.35-1.43)$ & $1.27(1.23-1.31)$ \\
\hline 3 & $1.36(1.32-1.40)$ & $1.33(1.29-1.38)$ & $1.24(1.20-1.28)$ \\
\hline 4 & $1.36(1.31-1.41)$ & $1.34(1.28-1.40)$ & $1.23(1.17-1.29)$ \\
\hline$\geq 5$ & $1.32(1.26-1.38)$ & $1.35(1.28-1.42)$ & $1.24(1.18-1.31)$ \\
\hline \multicolumn{4}{|c|}{ 30-day mortality } \\
\hline \multicolumn{4}{|c|}{ ACB score } \\
\hline 0 & 1 (reference) & 1 (reference) & 1 (reference) \\
\hline 1 & $1.42(1.33-1.52)$ & $1.38(1.27-1.51)$ & $1.28(1.17-1.39)$ \\
\hline 2 & $1.64(1.52-1.77)$ & $1.65(1.50-1.82)$ & $1.46(1.32-1.61)$ \\
\hline 3 & $1.50(1.38-1.64)$ & $1.60(1.43-1.80)$ & $1.44(1.28-1.61)$ \\
\hline 4 & $1.51(1.35-1.69)$ & $1.38(1.19-1.61)$ & $1.23(1.06-1.43)$ \\
\hline$\geq 5$ & $1.51(1.33-1.71)$ & $1.49(1.26-1.76)$ & $1.32(1.12-1.56)$ \\
\hline \multicolumn{4}{|c|}{ 1-year mortality } \\
\hline \multicolumn{4}{|c|}{ ACB score } \\
\hline 0 & 1 (reference) & 1 (reference) & 1 (reference) \\
\hline 1 & $1.31(1.27-1.36)$ & $1.28(1.23-1.33)$ & $1.19(1.14-1.24)$ \\
\hline 2 & $1.52(1.47-1.58)$ & $1.50(1.43-1.57)$ & $1.34(1.28-1.41)$ \\
\hline 3 & $1.44(1.38-1.51)$ & $1.40(1.32-1.47)$ & $1.27(1.20-1.34)$ \\
\hline 4 & $1.45(1.37-1.54)$ & $1.37(1.27-1.46)$ & $1.23(1.15-1.32)$ \\
\hline$\geq 5$ & $1.41(1.33-1.51)$ & $1.38(1.28-1.49)$ & $1.25(1.16-1.35)$ \\
\hline
\end{tabular}

Model 1: adjusted for Barthel Index, age, marital status, period of index admission, BMI, and hospital admissions 1 year prior to index date. Model 2: adjusted for Barthel Index, age, marital status, period of index admission, BMI, hospital admissions 1 year prior to index date, and Charlson comorbidity index

$N=56,564$

$A C B$ Anticholinergic cognitive burden, $B M I$ body mass index, $C I$ confidence interval, $H R$ hazard ratio

[1.32-1.50]) and model 2 (1.29 [1.21-1.38]) (Supplementary Table 2a, see ESM). For men, the highest overall risk of mortality (HR [95\% CI]) in both models was seen with an ACB score of 4: model 1 (1.49 [1.39-1.61]) and model 2 (1.39 [1.30-1.50]) (Supplementary Table 2b, see ESM). Figure 2 shows the relationship between the ACB score and risk of mortality in model 2 with a significant dose-response relationship before levelling off when a score of 2 is reached.

When assessing the total number of DAP, a significant increase in overall mortality was also seen in both the uni- and multivariable analyses (Table 3; Supplementary Table $3 a$ and $3 b$, see ESM). Figure 3 shows the relationship between the number of DAP and risk of mortality with a significant dose-response relationship with increasing number of anticholinergic medications before levelling off when number of medications reaches 4 . Figure $1 \mathrm{~b}$ shows a ROC curve of model 2 overall mortality for number of DAP in the total cohort with an AUC of 0.7888. No clinically relevant difference was seen between the ROC curves assessing either ACB score or number of DAP (AUC 0.7884 vs AUC 0.7888).

\section{Discussion}

In the present study, we found that the use of DAP at hospital admission is significantly associated with both shortand long-term mortality in older geriatric patients when taking comorbidities and ADL into account. This was seen both when using the ACB score and counting the number of DAP. The ACB score shows a dose-response relationship until a score of two, whilst the number of DAP shows a dose-response relationship with increasing number of medications.

\subsection{Context}

\subsubsection{Quantifying Anticholinergic Drug Burden}

In this study, we used the ACB score to quantify the anticholinergic drug burden. Several other scales have been developed with varying rationale and use. They differ in association between anticholinergic burden and adverse outcomes [12]. A recent study assessed the different scales, with the ACB score considered to be the scale of the best quality [41]. Also, another recent study found that out of eight anticholinergic-specific measures, the ACB score was the best for assessing the association between DAP and mortality in older people [42].

Existing literature has examined the association between ACB score and mortality in different settings and with mixed results. The settings include general population [10], community-dwellings [25], nursing homes [22], patients with dementia [24], and older patients admitted to hospital [11, $20,21,23,26]$. Generally, studies with follow-up longer than a year were successful in demonstrating the association between ACB score and mortality [10, 20-25]. One study examining the association on 3- and 7-day in-hospital mortality [26] and another examining this association 12 months following hospital discharge [11] did not demonstrate a relationship. In our study, we demonstrated a significant relationship between ACB score and mortality after 
$\mathbf{a}$

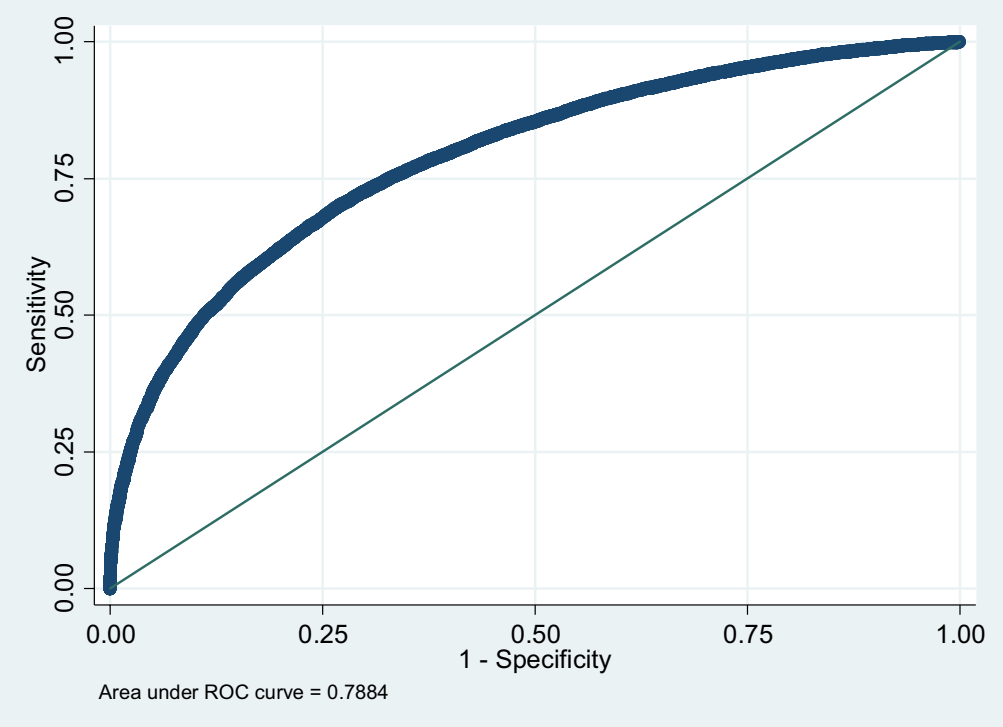

*Model 2: Adjusted for Barthel Index, age, marital status, period of index admission, BMI, hospital admissions one year prior to index date, and Charlson comorbidity index $(n=56,564)$

Abbreviations: ROC, Receiver operating characteristic

b

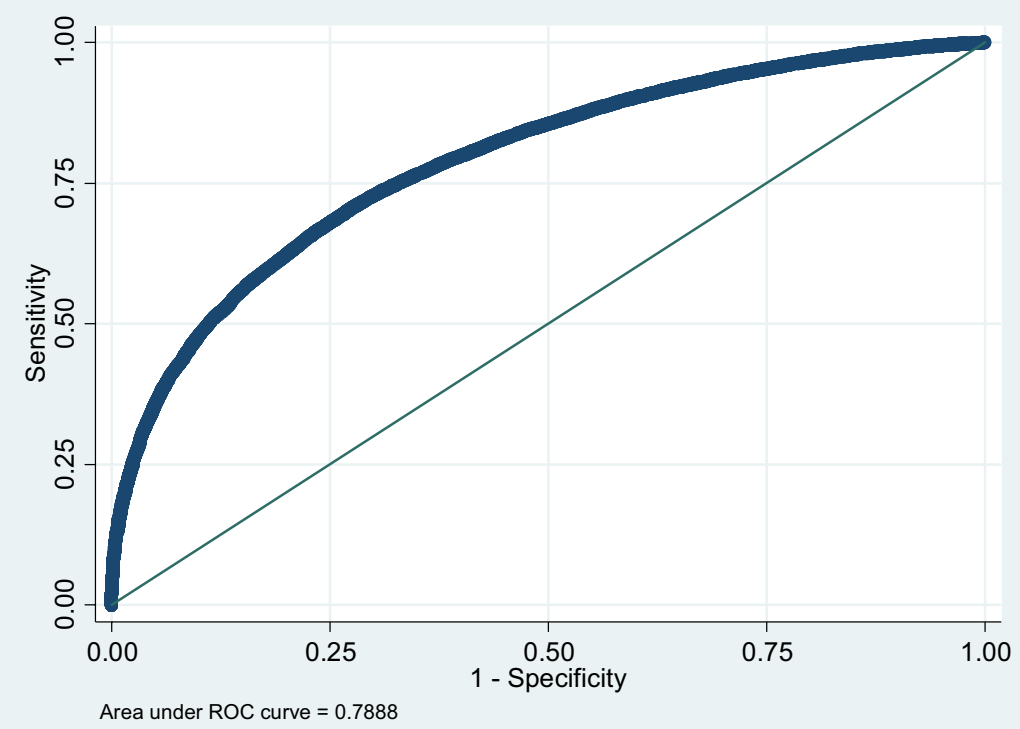

*Model 2: Adjusted for Barthel Index, age, marital status, period of index admission, BMI, hospital admissions one year prior to index date, and Charlson comorbidity index $(n=56,564)$

Abbreviations: ROC, Receiver operating characteristic

Fig. 1 Receiver operating characteristic curve for the association between drugs with anticholinergic properties and mortality for the fully adjusted model $2 *$ illustrated separately for the anticholinergic

both 30 days and 1 year after hospitalization, and is to our knowledge the first to do so using the ACB score. cognitive burden score (a) and number of drugs with anticholinergic properties (b)

In studies demonstrating increased mortality, only limited data on a potential dose-response relationship were available. Most studies included hazard ratios for ACB 


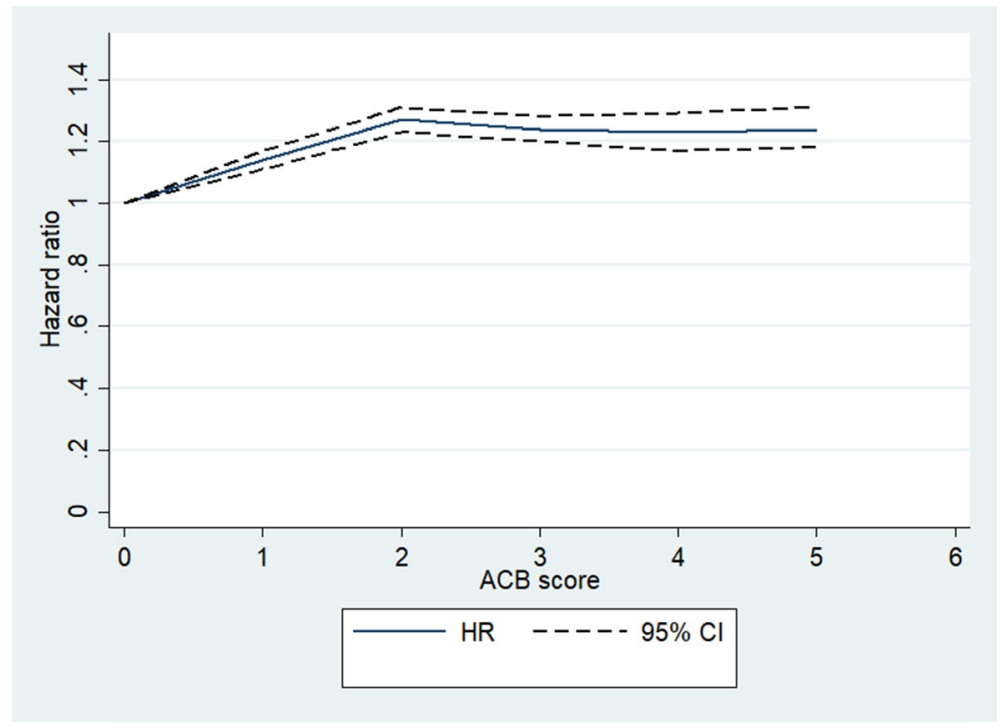

*Model 2: Adjusted for Barthel Index, age, marital status, period of index admission, BMI, hospital admissions one year prior to index date, and Charlson comorbidity index $(n=56,564)$ Abbreviations: CI, Confidence Interval; HR, Hazard Ratio

Fig. 2 Risk of overall mortality in the total cohort and anticholinergic cognitive burden score in the fully adjusted model $2^{*}$

scores of 1 and $\geq 2$ compared with ACB score of 0 [20, 22-24]. One study categorized the scores into 1, 2-3, and $\geq 4$ [10] and yet another only showed hazard ratios for increasing ACB score by one unit [25]. In this study, we included hazard ratios for both ACB score and number of DAP with categorizations from 0 to $\geq 5$. Counting the number of DAP showed a similar dose-response relationship as when using the ACB score and none of the measures had a continuous dose-response relationship. One other study addressed the total number of DAP and impact on mortality among long-term care facility residents [43]. The study used three different approaches to identify anticholinergic drugs and found a similar tendency with number of DAP associated with mortality. To our knowledge, no other studies so far have looked at the association between anticholinergic polypharmacy and mortality using ACB score in hospitalized patients. The association found in the present study cannot be explained by polypharmacy alone. In a prior study using data from the same cohort as the current study, the association between number of total medications and mortality was assessed [44]. The study found an increased risk of mortality with five or more medications prescribed whereas the use of one to four medications was not significantly associated with mortality. An Australian study assessing older men also reported that the use of five or more medications was associated with mortality [45]. In the current study, the number of DAP was significantly associated with mortality even with only one medication prescribed. This suggests an important anticholinergic component when assessing the association between polypharmacy in general and mortality.

\subsubsection{Independent Association Between the Use of DAP and Mortality}

In the present study, we found an independent association between the use of DAP at hospital admission and mortality, even when adjusting for several important risk factors in the multivariable analyses including ADL and different ways of expressing comorbidity. We have no data to explore the specific mechanism behind why DAP affect mortality in older people. However, several other studies have explored this. Changes in the permeability of the blood-brain barrier as well as changes in pharmacokinetics and pharmacodynamics with increasing age make older people more susceptible to unfavorable effects from DAP [5]. These adverse effects vary widely. Some studies found an association between the use of DAP in older people and neurological symptoms such as confusion, agitation, and coma [46]. Some evidence suggests that DAP may contribute to cardiovascular events via their ability to decrease the heart rate variability [46, 47], their inhibition of the parasympathetic control of the heart [48], or their pro-arrhythmic and pro-ischemic effect [49]. Other 
Table 3 Univariable and multivariable hazard ratios and corresponding $95 \%$ confidence intervals for overall, 30-day, and 1-year mortality according to the number of drugs with anticholinergic properties in the total cohort

\begin{tabular}{|c|c|c|c|}
\hline & \multirow[t]{2}{*}{$\begin{array}{l}\text { Univariable } \\
\text { HR }(95 \% \text { CI })\end{array}$} & \multicolumn{2}{|l|}{$\begin{array}{l}\text { Multivariable } \\
\text { HR }(95 \% \text { CI })\end{array}$} \\
\hline & & Model 1 & Model 2 \\
\hline \multicolumn{4}{|c|}{ Overall mortality } \\
\hline \multicolumn{4}{|c|}{ No. of DAP } \\
\hline 0 & 1 (reference) & 1 (reference) & 1 (reference) \\
\hline 1 & $1.19(1.17-1.22)$ & $1.18(1.15-1.21)$ & $1.12(1.09-1.15)$ \\
\hline 2 & $1.37(1.34-1.41)$ & $1.37(1.33-1.40)$ & $1.25(1.22-1.29)$ \\
\hline 3 & $1.50(1.45-1.55)$ & $1.49(1.43-1.55)$ & $1.35(1.30-1.40)$ \\
\hline 4 & $1.57(1.49-1.65)$ & $1.57(1.48-1.66)$ & $1.39(1.32-1.47)$ \\
\hline$\geq 5$ & $1.57(1.44-1.71)$ & $1.64(1.48-1.81)$ & $1.44(1.31-1.59)$ \\
\hline \multicolumn{4}{|c|}{ 30-day mortality } \\
\hline \multicolumn{4}{|c|}{ No. of DAP } \\
\hline 0 & 1 (reference) & 1 (reference) & 1 (reference) \\
\hline 1 & $1.36(1.28-1.45)$ & $1.33(1.22-1.45)$ & $1.24(1.14-1.35)$ \\
\hline 2 & $1.57(1.46-1.69)$ & $1.56(1.42-1.71)$ & $1.39(1.27-1.53)$ \\
\hline 3 & $1.71(1.56-1.87)$ & $1.85(1.65-2.08)$ & $1.59(1.42-1.79)$ \\
\hline 4 & $1.78(1.56-2.03)$ & $1.75(1.48-2.08)$ & $1.50(1.26-1.78)$ \\
\hline$\geq 5$ & $1.73(1.37-2.18)$ & $1.72(1.28-2.30)$ & $1.46(1.09-1.95)$ \\
\hline \multicolumn{4}{|c|}{ 1-year mortality } \\
\hline \multicolumn{4}{|c|}{ No. of DAP } \\
\hline 0 & 1 (reference) & 1 (reference) & 1 (reference) \\
\hline 1 & $1.26(1.22-1.31)$ & $1.23(1.18-1.28)$ & $1.15(1.11-1.20)$ \\
\hline 2 & $1.46(1.41-1.51)$ & $1.44(1.37-1.50)$ & $1.29(1.24-1.35)$ \\
\hline 3 & $1.64(1.57-1.72)$ & $1.62(1.53-1.71)$ & $1.42(1.34-1.50)$ \\
\hline 4 & $1.72(1.61-1.84)$ & $1.67(1.54-1.81)$ & $1.45(1.34-1.57)$ \\
\hline$\geq 5$ & $1.72(1.53-1.94)$ & $1.72(1.50-1.97)$ & $1.48(1.29-1.70)$ \\
\hline
\end{tabular}

Model 1: adjusted for Barthel Index, age, marital status, period of index admission, BMI, and hospital admissions 1 year prior to index date. Model 2: adjusted for Barthel Index, age, marital status, period of index admission, BMI, hospital admissions 1 year prior to index date, and Charlson comorbidity index

$N=56,564$

$B M I$ body mass index, $C I$ confidence interval, $D A P$ drugs with anticholinergic properties, $H R$ hazard ratio

studies have also found an association between the inhibition of the muscarinic receptors via DAP and an increase in inflammatory processes [50].

In this study, the DAP with a score of one counted for most of the intake, and risk of mortality was increased already with a score of one. This shows that DAP at hospital admission have a clinically relevant impact even with a score of one and a revision of the system for scoring DAP might be warranted when assessing mortality. A similar trend in the distribution of DAP was seen in other studies [21, 23, 25]. This finding is of relevance for hospital doctors and other health care professionals when performing a medical review of older hospitalized patients.

\subsection{Strengths and Limitations}

The present study has various strengths. To our knowledge, this is the first nationwide longitudinal cohort study to assess the association between DAP and mortality taking into account several important risk factors including ADL. Furthermore, the study allowed a long follow-up of 11 years. The validity of the results was increased due to no patients lost to follow-up throughout the study period. This was attained via accurate linkage at the personal level between the many nationwide population-based Danish health registers.

The present study also has several limitations. First, the ACB score is not customized to Danish medicine. This means that some DAP used in Denmark may not be considered. Second, we have no data either on comorbidities or DAP (including dose, duration, or number) after index date. In this way, potential development of additional comorbidities or changes in use of medications following discharge might not have been captured. However, the association with use of DAP upon admission was still associated with both short- and long-term mortality. Third, the CCI in our study is calculated using prior ICD-10 diagnoses. These diagnoses are obtained from the health registers and based on data from hospital discharge, which may have introduced information bias. However, the use of Danish national health registers to calculate $\mathrm{CCI}$ have shown high validity in a prior study [51]. Fourth, due to our observational design it is difficult to explore whether DAP are associated with mortality or serve as a proxy for severity of diseases and we cannot rule out the risk of confounding by indication. However, the vast majority of DAP used among patients was given due to heart diseases. In our fully adjusted model we included CCI, which takes both several heart diseases and their severity into account and still found a persistent association between the use of DAP and mortality. Despite these efforts, residual effects might, however, still be present. Also, we cannot rule out that some of DAP are prescribed to manage symptoms in end of life and in this context can even be considered appropriate. Finally, there is no gold standard for quantifying anticholinergic burden and the use of other scales might not have shown similar results. However, prior evidence shows that the ACB score is of most value when assessing the association between DAP and mortality in older people [42]. 


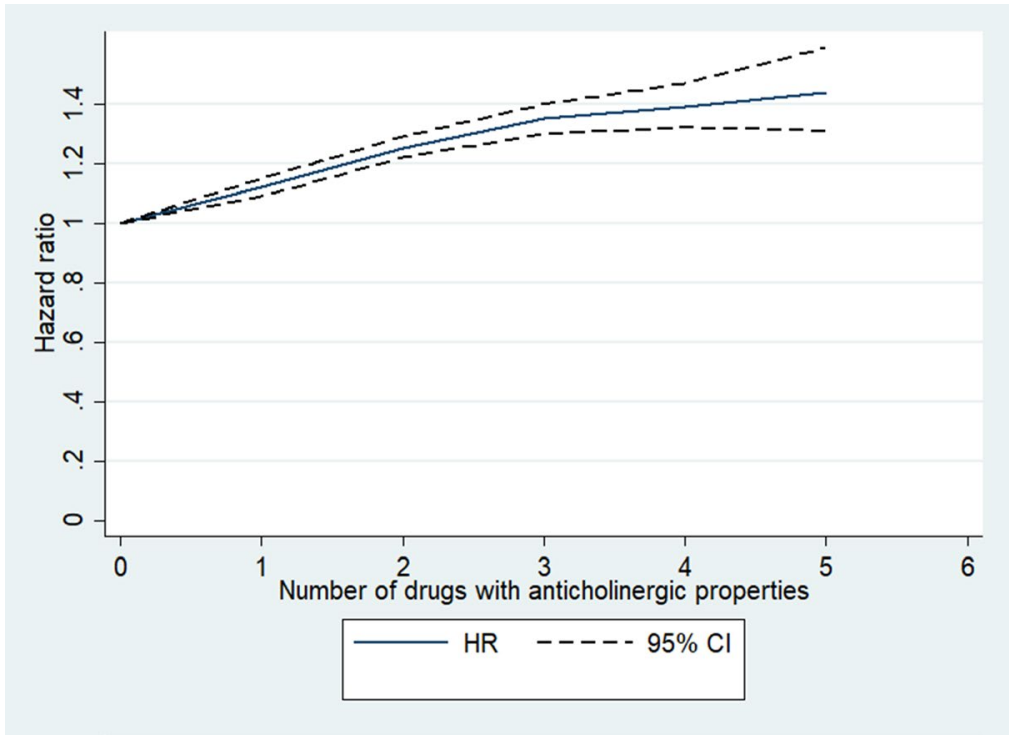

*Model 2: Adjusted for Barthel Index, age, marital status, period of index admission, BMI, hospital admissions one year prior to index date, and Charlson comorbidity index $(n=56,564)$

Abbreviations: CI, Confidence Interval; HR, Hazard Ratio

Fig. 3 Risk of overall mortality in the total cohort and number of drugs with anticholinergic properties in the fully adjusted model $2 *$

\section{Conclusion and Implications}

This study demonstrated a significant association between the use of DAP at hospital admission and all-cause mortality in older geriatric patients even when adjusting for other important variables such as comorbidity and ADL. Assessing either ACB score or the number of DAP showed similar dose-response relationships. This reveals that in terms of mortality, the simple counting of the number of DAP might be just as important as calculating the ACB score. Our study may ease the feasibility of deprescribing for clinicians, as a simple cumulative count of DAP is easier to administer than calculating an ACB score. Reduction of the use of DAP is feasible but challenging in a real-life setting [52] and a gap still exists in the literature on the effects on mortality of reducing the use of DAP prescribed for older adults. While awaiting RCT studies on deprescribing, initiation of pragmatic studies with focus on the effect of stopping these medications on both clinical and implementation outcomes should be encouraged as well as further analyses of observational data in order to better understand which harmful effects or adverse drug events in general might potentially be reversed.

Supplementary Information The online version contains supplementary material available at https://doi.org/10.1007/s40801-021-00270-7.

\section{Declarations}

Funding This work was supported by the Program for Clinical Research Infrastructure (PROCRIN) established by the Lundbeck Foundation and the Novo Nordisk Foundation [Grant number: R3-017]. The funders were not involved in the design and conduct of the study; collection, management, analysis, and interpretation of the data; preparation, review, or approval of the manuscript; and decision to submit the manuscript for publication.

Conflict of interest Dr. Ryg reports an unrestricted research grant from Program for Clinical Research Infrastructure (PROCRIN) established by the Lundbeck Foundation and the Novo Nordisk Foundation, during the conduct of the study [Grant number: R3-017]. All authors declare no personal conflict of interest regarding the present study.

Ethics approval Approval from an ethical committee was not needed according to Danish legislation due to the epidemiological study design.

Consent to participate According to Danish legislation, informed consent was not needed from patients due to the retrospective cohort design.

Consent for publication Not applicable.

Availability of data and material According to the Danish Law on personal data, it is not allowed to make the dataset publicly available. Access to data from the Danish Health Data Authority requires association with a Danish research unit and approval from the Danish Data Protection Agency (http://www.datatilsynet.dk/english/) and the National Health Service Register (http://www.sundhedsdatastyrelsen. $\mathrm{dk} / \mathrm{da} /$ forskerservice [in Danish]).

Code availability Not applicable. 
Author contributions JR and PLA had full access to all the data in the study and take responsibility for the integrity of the data and the accuracy of the data analysis. SRS, JDF, TM, PM, and JR designed the study. PLA performed the statistical analyses in dialog with SRS, JDF, and JR. All authors (SRS, JDF, PLA, TM, MP, JUR, JR) were involved in the interpretation of data. SRS and JDF wrote the first manuscript draft and all authors (SRS, JDF, PLA, TM, MP, JUR, JR) were involved in the critical revision of the manuscript. JR had the primary responsibility for the final content but all authors (SRS, JDF, PLA, TM, MP, JUR, JR) are accountable for the aspects of the work. All authors (SRS, JDF, PLA, TM, MP, JUR, JR) read and approved the final manuscript.

Open Access This article is licensed under a Creative Commons Attribution-NonCommercial 4.0 International License, which permits any non-commercial use, sharing, adaptation, distribution and reproduction in any medium or format, as long as you give appropriate credit to the original author(s) and the source, provide a link to the Creative Commons licence, and indicate if changes were made. The images or other third party material in this article are included in the article's Creative Commons licence, unless indicated otherwise in a credit line to the material. If material is not included in the article's Creative Commons licence and your intended use is not permitted by statutory regulation or exceeds the permitted use, you will need to obtain permission directly from the copyright holder. To view a copy of this licence, visit http://creativecommons.org/licenses/by-nc/4.0/.

\section{References}

1. United Nations, Department of Economic and Social Affairs, Population Division (2019). In: World population ageing 2019: highlights (ST/ESA/SER.A/430). United Nations. 2019. https:// www.un.org/en/development/desa/population/publications/pdf/ ageing/WorldPopulationAgeing2019-Report.pdf. Accessed 14 Dec 2020.

2. Barnett K, Mercer SW, Norbury M, Watt G, Wyke S, Guthrie B. Epidemiology of multimorbidity and implications for health care, research, and medical education: a cross-sectional study. Lancet. 2012;380(9836):37-43. https://doi.org/10.1016/S0140-6736(12) 60240-2.

3. Kantor ED, Rehm CD, Haas JS, Chan AT, Giovannucci EL. Trends in prescription drug use among adults in the United States from 1999-2012. JAMA. 2015;314(17):1818-31. https://doi.org/ 10.1001/jama.2015.13766.

4. Dagli RJ, Sharma A. Polypharmacy: a global risk factor for elderly people. J Int Oral Health. 2014;6(6):i-ii.

5. Corsonello A, Pedone C, Incalzi RA. Age-related pharmacokinetic and pharmacodynamic changes and related risk of adverse drug reactions. Curr Med Chem. 2010;17(6):571-84. https://doi.org/ 10.2174/092986710790416326.

6. Nakham A, Myint PK, Bond CM, Newlands R, Loke YK, Cruickshank $M$. Interventions to reduce anticholinergic burden in adults aged 65 and older: a systematic review. J Am Med Dir Assoc. 2020;21(2):172-80.e5. https://doi.org/10.1016/j.jamda.2019.06. 001.

7. van der Meer HG, Wouters H, Pont LG, Taxis K. Reducing the anticholinergic and sedative load in older patients on polypharmacy by pharmacist-led medication review: a randomised controlled trial. BMJ Open. 2018;8(7): e019042. https://doi.org/10. 1136/bmjopen-2017-019042.

8. Kouladjian O'Donnell L, Dearing ME. Should hospital admission be used as an opportunity for deprescribing in older adults? Can J Hosp Pharm. 2020. https://doi.org/10.4212/cjhp.v73i4.3029.
9. Fox C, Smith T, Maidment I, Chan WY, Bua N, Myint PK, et al. Effect of medications with anti-cholinergic properties on cognitive function, delirium, physical function and mortality: a systematic review. Age Ageing. 2014;43(5):604-15. https://doi.org/10.1093/ ageing/afu096.

10. Myint PK, Fox C, Kwok CS, Luben RN, Wareham NJ, Khaw KT. Total anticholinergic burden and risk of mortality and cardiovascular disease over 10 years in 21,636 middle-aged and older men and women of EPIC-norfolk prospective population study. Age Ageing. 2015;44(2):219-25. https://doi.org/10.1093/ageing/ afu185.

11. Rigor J, Rueff Rato I, Ferreira PM, Pereira R, Ribeiro C, Teixeira D, et al. Prehospital anticholinergic burden is associated with delirium but not with mortality in a population of acutely Ill medical patients. J Am Med Dir Assoc. 2020;21(4):481-5. https://doi. org/10.1016/j.jamda.2019.12.018.

12. Welsh TJ, van der Wardt V, Ojo G, Gordon AL, Gladman JRF. Anticholinergic drug burden tools/scales and adverse outcomes in different clinical settings: a systematic review of reviews. Drugs Aging. 2018;35(6):523-38. https://doi.org/10.1007/ s40266-018-0549-z.

13. Lieberman JA 3rd. Managing anticholinergic side effects. Prim Care Companion J Clin Psychiatry. 2004;6(Suppl 2):20-3.

14. Hilmer SN. A Drug Burden Index to define the functional burden of medications in older people. Arch Intern Med. 2007;167(8):781. https://doi.org/10.1001/archinte.167.8.781.

15. Carnahan RM, Lund BC, Perry PJ, Pollock BG, Culp KR. The Anticholinergic Drug Scale as a measure of drug-related anticholinergic burden: associations with serum anticholinergic activity. J Clin Pharmacol. 2006;46(12):1481-6. https://doi.org/ $10.1177 / 0091270006292126$.

16. Rudolph JL, Salow MJ, Angelini MC, McGlinchey RE. The Anticholinergic Risk Scale and anticholinergic adverse effects in older persons. Arch Intern Med. 2008;168(5):508-13. https:// doi.org/10.1001/archinternmed.2007.106.

17. Boustani M, Campbell N, Munger S, Maidment I, Fox C. Impact of anticholinergics on the aging brain: a review and practical application. Aging Health. 2008;4(3):311-20. https://doi.org/ 10.2217/1745509X.4.3.311.

18. Lozano-Ortega G, Johnston KM, Cheung A, Wagg A, Campbell NL, Dmochowski RR, et al. A review of published anticholinergic scales and measures and their applicability in database analyses. Arch Gerontol Geriatr. 2020;87: 103885. https://doi. org/10.1016/j.archger.2019.05.010.

19. Hanlon P, Quinn TJ, Gallacher KI, Myint PK, Jani BD, Nicholl BI, et al. Assessing risks of polypharmacy involving medications with anticholinergic properties. Ann Fam Med. 2020;18(2):148. https://doi.org/10.1370/afm.2501.

20. Lattanzio F, Corica F, Schepisi R, Amantea D, Bruno F, Cozza A, et al. Anticholinergic burden and 1-year mortality among older patients discharged from acute care hospital: ACB score and mortality. Geriatr Gerontol Int. 2018. https://doi.org/10. 1111/ggi.13234.

21. Corsonello A, Cozza A, D'Alia S, Onder G, Volpato S, Ruggiero C, et al. The excess mortality risk associated with anticholinergic burden among older patients discharged from acute care hospital with depressive symptoms. Eur J Intern Med. 2019;61:69-74. https://doi.org/10.1016/j.ejim.2018.11.004.

22. Vetrano DL, La Carpia D, Grande G, Casucci P, Bacelli T, Bernabei R, et al. Anticholinergic medication burden and 5-year risk of hospitalization and death in nursing home elderly residents with coronary artery disease. J Am Med Dir Assoc. 2016;17(11):1056-9. https://doi.org/10.1016/j.jamda.2016.07. 012.

23. Lattanzio F, Onder G, La Fauci MM, Volpato S, Cherubini A, Fabbietti P, et al. Anticholinergic burden is associated with 
increased mortality in older patients with dependency discharged from hospital. J Am Med Dir Assoc. 2018;19(11):942-7. https:// doi.org/10.1016/j.jamda.2018.06.012.

24. Tan E, Eriksdotter M, García-Ptacek S, Fastbom J, Johnell K. Anticholinergic burden and risk of stroke and death in people with different types of dementia. J Alzheimers Dis. 2018;65:1-8. https://doi.org/10.3233/JAD-180353.

25. Cross AJ, George J, Woodward MC, Ames D, Brodaty H, Wolfe $\mathrm{R}$, et al. Potentially inappropriate medication, anticholinergic burden, and mortality in people attending memory clinics. J Alzheimers Dis. 2017;60(2):349-58. https://doi.org/10.3233/jad-170265.

26. Kidd AC, Musonda P, Soiza RL, Butchart C, Lunt CJ, Pai Y, et al. The relationship between total anticholinergic burden (ACB) and early in-patient hospital mortality and length of stay in the oldest old aged 90 years and over admitted with an acute illness. Arch Gerontol Geriatr. 2014;59(1):155-61. https://doi.org/10.1016/j. archger.2014.01.006.

27. Ryg J, Engberg H, Mariadas P, Pedersen SGH, Jorgensen MG, Vinding KL, et al. Barthel Index at hospital admission is associated with mortality in geriatric patients: a Danish nationwide population-based cohort study. Clin Epidemiol. 2018;10:1789-800. https://doi.org/10.2147/clep.S176035.

28. Ryg J, Engberg H, Anru PL, Pedersen SGH, Jorgensen MG, Vinding KL, et al. Activities of daily living at hospital admission and estimated survival time of older patients. Age Ageing. 2020. https://doi.org/10.1093/ageing/afaa251.

29. Storeng SH, Vinjerui KH, Sund ER, Krokstad S. Associations between complex multimorbidity, activities of daily living and mortality among older Norwegians. A prospective cohort study: the HUNT study, Norway. BMC Geriatr. 2020;20(1):21. https:// doi.org/10.1186/s12877-020-1425-3.

30. Johnston MC, Black C, Mercer SW, Prescott GJ, Crilly MA. Prevalence of secondary care multimorbidity in mid-life and its association with premature mortality in a large longitudinal cohort study. BMJ Open. 2020;10(5): e033622. https://doi.org/10.1136/ bmjopen-2019-033622.

31. Schmidt M, Pedersen L, Sørensen HT. The Danish civil registration system as a tool in epidemiology. Eur J Epidemiol. 2014;29(8):541-9. https://doi.org/10.1007/s10654-014-9930-3.

32. Johannesdottir SA, Horváth-Puhó E, Ehrenstein V, Schmidt M, Pedersen L, Sørensen HT. Existing data sources for clinical epidemiology: the Danish national database of reimbursed prescriptions. Clin Epidemiol. 2012;4:303-13. https://doi.org/10.2147/ clep.S37587.

33. Kannegaard PN, Vinding KL, Hare-Bruun H. National database of geriatrics. Clin Epidemiol. 2016;8:731-5. https://doi.org/10. 2147/clep.S99473.

34. Schmidt M, Schmidt SAJ, Sandegaard JL, Ehrenstein V, Pedersen L, Sørensen HT. The Danish national patient registry: a review of content, data quality, and research potential. Clin Epidemiol. 2015;7:449-90. https://doi.org/10.2147/CLEP.S91125.

35. Charlson ME, Pompei P, Ales KL, MacKenzie CR. A new method of classifying prognostic comorbidity in longitudinal studies: development and validation. J Chronic Dis. 1987;40(5):373-83. https://doi.org/10.1016/0021-9681(87)90171-8.

36. Shah S, Vanclay F, Cooper B. Improving the sensitivity of the Barthel Index for stroke rehabilitation. J Clin Epidemiol. 1989;42(8):703-9. https://doi.org/10.1016/0895-4356(89) 90065-6.

37. Danish National Health Board. SKSbrowser. Danish version of the statistical classification of diseases. 2017. http://medinfo.dk/ sks/brows.php. Accessed 09 Dec 2020.

38. Larsen MD, Rosholm JU, Hallas J. The influence of comprehensive geriatric assessment on drug therapy in elderly patients. Eur J Clin Pharmacol. 2014;70(2):233-9. https://doi.org/10.1007/ s00228-013-1601-x.
39. Aging Brain Care. Anticholinergic cognitive burden scale-2012 update. J Am Geriatr Soc. 2013. http://www.idhca.org/wp-conte nt/uploads/2018/02/DESAI_ACB_scale_-_Legal_size_paper.pdf. Accessed 14 Dec 2020.

40. Elm EV, Altman DG, Egger M, Pocock SJ, Gøtzsche PC, Vandenbroucke JP. Strengthening the reporting of observational studies in epidemiology (STROBE) statement: guidelines for reporting observational studies. BMJ. 2007;335(7624):806-8. https://doi. org/10.1136/bmj.39335.541782.AD.

41. Lisibach A, Benelli V, Ceppi MG, Waldner-Knogler K, Csajka C, Lutters M. Quality of anticholinergic burden scales and their impact on clinical outcomes: a systematic review. Eur J Clin Pharmacol. 2020. https://doi.org/10.1007/s00228-020-02994-x.

42. Graves-Morris K, Stewart C, Soiza RL, Taylor-Rowan M, Quinn TJ, Loke YK, et al. The prognostic value of anticholinergic burden measures in relation to mortality in older individuals: a systematic review and meta-analysis. Front Pharmacol. 2020;11:570. https:// doi.org/10.3389/fphar.2020.00570.

43. Aalto UL, Finne-Soveri H, Kautiainen H, Roitto H-M, Öhman $\mathrm{H}$, Pitkälä KH. Use of anticholinergic drugs according to various criteria and their association with psychological well-being and mortality in long-term care facilities. J Am Med Dir Assoc. 2019;20(9):1156-62. https://doi.org/10.1016/j.jamda.2019.02. 007.

44. Brockhattingen KK, Anru PL, Masud T, Petrovic M, Ryg J. Association between number of medications and mortality in geriatric inpatients: a Danish nationwide register-based cohort study. Eur Geriatr Med. 2020. https://doi.org/10.1007/s41999-020-00390-3.

45. Gnjidic D, Hilmer SN, Blyth FM, Naganathan V, Waite L, Seibel MJ, et al. Polypharmacy cutoff and outcomes: five or more medicines were used to identify community-dwelling older men at risk of different adverse outcomes. J Clin Epidemiol. 2012;65(9):98995. https://doi.org/10.1016/j.jclinepi.2012.02.018.

46. Collamati A, Martone AM, Poscia A, Brandi V, Celi M, Marzetti E, et al. Anticholinergic drugs and negative outcomes in the older population: from biological plausibility to clinical evidence. Aging Clin Exp Res. 2016;28(1):25-35. https://doi.org/10.1007/ s40520-015-0359-7.

47. O'Brien P, Oyebode F. Psychotropic medication and the heart. Adv Psychiatr Treat. 2003;9(6):414-23. https://doi.org/10.1192/ apt.9.6.414.

48. Parlow JL, van Vlymen JM, Odell MJ. The duration of impairment of autonomic control after anticholinergic drug administration in humans. Anesth Analg. 1997;84(1):155-9. https://doi.org/10. 1097/00000539-199701000-00028.

49. Singh S, Loke YK, Enright P, Furberg CD. Pro-arrhythmic and pro-ischaemic effects of inhaled anticholinergic medications. Thorax. 2013;68(1):114. https://doi.org/10.1136/thora xjnl-2011-201275.

50. Razani-Boroujerdi S, Behl M, Hahn FF, Pena-Philippides JC, Hutt J, Sopori ML. Role of muscarinic receptors in the regulation of immune and inflammatory responses. J Neuroimmunol. 2008;194(1-2):83-8. https://doi.org/10.1016/j.jneuroim.2007.11. 019.

51. Thygesen SK, Christiansen CF, Christensen S, Lash TL, Sørensen HT. The predictive value of ICD-10 diagnostic coding used to assess Charlson comorbidity index conditions in the populationbased Danish national registry of patients. BMC Med Res Methodol. 2011;11:83. https://doi.org/10.1186/1471-2288-11-83.

52. Ailabouni N, Mangin D, Nishtala PS. DEFEAT-polypharmacy: deprescribing anticholinergic and sedative medicines feasibility trial in residential aged care facilities. Int J Clin Pharm. 2019;41(1):167-78. https://doi.org/10.1007/s11096-019-00784-9. 